See discussions, stats, and author profiles for this publication at: https://www.researchgate.net/publication/353074063

\title{
PENGEMBANGAN POTENSI PARIWISATA RELIGI (STUDI KASUS PADA MAKAM SYEKH ABDURRAHMAN SIDDIQ DI DESA TELUK DALAM KECAMATAN KUALA INDRAGIRI KABUPATEN INDRAGIRI HILIR) DEVELOPME....
}

Article · July 2021

\section{CITATIONS}

0

3 authors, including:

- Ali Azhar

Islamic University of Indragiri

13 PUBLICATIONS 8 CITATIONS

SEE PROFILE
67

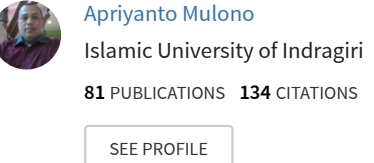

Some of the authors of this publication are also working on these related projects:

Fermentasi Biji Kakao Kering Menggunakan Saccharomyces cerevisiae, Lactobacillus lactis, dan Acetobacter aceti View project

Lahan Gambut dan Produksinya View project 


\title{
PENGEMBANGAN POTENSI PARIWISATA RELIGI (STUDI KASUS PADA MAKAM SYEKH ABDURRAHMAN SIDDIQ DI DESA TELUK DALAM KECAMATAN KUALA INDRAGIRI KABUPATEN INDRAGIRI HILIR)
}

\section{DEVELOPMENT OF THE POTENTIAL OF RELIGIOUS TOURISM(CASE STUDY ON THE TOMB OF SYEKH ABDURRAHMAN SIDDIQ IN TELUK VILLAGE IN KUALA INDRAGIRI DISTRICT, INDRAGIRI HILIR REGENCY)}

\author{
Ali Azhar ${ }^{1}$, Mulono Aprianto ${ }^{2}$ Bayu Fajar Sus anto ${ }^{3}$ \\ ${ }^{1}$ Universitas Is lam Indragiri \\ Sahabat.aliazhar@gmail.com \\ MulonoAprianto@gmail.com \\ Bayufajar14@gmail.com
}

Article Info

Article history:

Received

Revised

Accepted

\begin{abstract}
This study aims to describe the potential development of religious tourism at the tomb of Sheikh Abdurrahman Siddiq in Teluk Dalam Village, Kuala Indragiri District, Indragiri Hilir Regency, including the process of forming tourism objects, developing tourism objects, and the impact of their development. This research is a qualitative type with a case study strategy. Data collection techniques by observation, interviews, and documentation. Test the validity of the data by triangulation of data sources and data collection techniques. Analysis of the data using interactive techniques. This study shows that the formation of this tourist attraction stems from the collapse of the Indragiri kingdom. Sheikh Abdurrahman Siddiq, a Mufhti of the Indragiri Kingdom, built a mosque as a means of spreading Islam in the Hidayat area. After he died, he was buried in Teluk Dalam village in the courtyard of the mosque that was built. The tomb is sacred by the community and used as a religious tourism object. Many people visit for pilgrimage. For this reason, development is carried out, including the addition of tourist objects such as the Sheikh Abdurrahman Siddiq Museum and the Mosque to make it more comfortable. In addition, the addition of basic facilities in the form of an entrance gate and a roof to protect the tomb. Complementary facilities are in the form of pilgrim rules and mosques. Supporting facilities include parking lots, canteens, and clothing stores. However, there are several facilities that have not been developed optimally, namely repairing basic facilities in the form of repairing entrances to tombs and mosques. Improvement of complementary facilities in the form of ablution places and toilets. The development of tourist information includes introducing tourism objects to outsiders and to increase tourist visits. This can be done by using brochures, accessing google internet services. This development has a positive impact on the local economy. It can be seen from the growth of various business fields, such as clothing stores, food stalls, street vendors, and entertainment.
\end{abstract}




\section{Keywords:}

pengembangan

pariwisata

religi

\begin{abstract}
Abstrak (Bahasa Indonesia)
Penelitian ini bertujuan untuk mendeskripsikan pengembangan potensi parwisata religi pada makam Syekh Abdurrahman Siddiq Di Desa Teluk Dalam, Kecamatan Kuala Indragiri, Kabupaten Indragiri Hilir, meliputi proses terbentuknya obyek wisata, pengembangan obyek wisata, dan dampak pengembangannya. Penelitian ini berjenis kualitatif dengan strategi studi kasus. Teknik pengumpulan data dengan observasi, wawancara, dan dokumentasi. Uji keabsahan data dengan triangulasi sumber data dan teknik pengumpulan data. Analisis datanya menggunakan teknik interaktif. Penelitian ini menunjukkan bahwa terbentuknya obyek wisata ini bermula dari runtuhnya kerajaan Indragiri. Syekh Abdurrahman Siddiq merupakan seorang Mufhti Kerajaan Indragiri membangun masjid sebagai sarana menyebarkan agama Islam di wilayah Hidayat. Setelah meninggal dimakamkan di desa teluk dalam di halaman masjid yang dibangun. Makam tersebut dikeramatkan oleh masyarakat dan dijadikan obyek wisata religi. Banyak masyarakat berkunjung untuk ziarah. Untuk itu dilakukan pengembangan, meliputi penambahan obyek wisata seperti Museum Syekh Abdurrahman Siddiq dan Masjid agar lebih nyaman. Selain itu, penambahan sarana pokok berupa gapura pintu masuk dan atap untuk melindungi makam. Sarana pelengkap berupa tata tertib peziarah dan masjid. Sarana penunjang berupa tempatparkir, kantin, dan toko pakaian. Namun, ada beberapa sarana belum dikembangkan secara optimal yaitu perbaikan sarana pokok berupa perbaikan pintu masuk ke makam dan masjid.. Perbaikan sarana pelengkap berupa tempat wudhu dan toilet. Pengembangan informasi wisata meliputi memperkenalkan obyek wisata kepada pihak luar dan untuk meningkatkan kunjungan wisatawan. Hal tersebut dapat dilakukan dengan menggunakan brosur, akes layanan google internet. Dari pengembangan tersebut berdampak positif pada perekonomian masyarakat setempat. Terlihat dari tumbuhnya berbagai bidang usaha, seperti toko pakaian, warung makan, pedagang kaki lima, serta hiburan.
\end{abstract}

\title{
Corresponding Author:
}

\author{
Ali Azhar \\ Fakultas Hukum \\ Universitas Islam Indragiri \\ E-mail:
}

\section{PENDAHULUAN}

Indonesia merupakan negara kepulauan terbesar di dunia dengan kekayaan dan keanekaragaman alam yang membentang dari Sabang hingga Merauke. Keberagaman sumber daya alam yang dimiliki tersebut dapat menjadi modal untuk pariwisata apabila dapat dimanfaatkan dengan baik sesuai potensinya. Sebagai suatu industri, pariwisata dianggap sebagai sektor penyelamat dan menjadi primadona karena hampir selama dua dekade terakhir, pertumbuhan sektor pariwisata di Indonesia semakin baik dan stabil sebagai penghasil devisa negara.

Enam alasan mengapa pariwisata perlu untuk dikembangkan terutama bagi negara sedang berkembang seperti Indonesia. Pertama, adanya motivasi seseorang untuk berwisata merupakan peluang bagi suatu wilayah dengan potensi wisata untuk menjadi media pemenuhan kebutuhan. Kedua, dengan menjadi media 
pemenuhan kebutuhan tersebut, maka ada berbagai keuntungan yang dapat diraih. Ketiga, bagi negara sedang berkembang, industri pariwisata merupakan media pembangunan ekonomi yang tidak memerlukan investasi besar dalam jangka panjang. Keempat, sektor pariwisata dapat mengurangi ketergantungan impor karena barang modal dan barang habis pakai dapat disediakan oleh destinasi pariwisata. Kelima, peran pariwisata yang sangat besar dalam perekonomian dunia memberi peluang yang lebih besar bagi Indonesia untuk menarik segmen pasar dari negara-negara maju. Keenam, industri pariwisata dapat mengurangi tingkat kemiskinan.

Cukup banyak jenis dan obyek pariwisata yang ditawarkan mulai dari wis ata budaya, wisata pendidikan, wisata religi hingga wisata minat khusus. Salah satu potensi wisata yang berkembang saat ini adalah wisata religi atau yang disebut dengan ziarah. Wisata religi merupakan kegiatan melakukan perjalanan dengan tujuan mendapatkan kenikmatan, kepuasan serta pengetahuan. Wisata religi banyak dilakukan oleh perorangan atau rombongan ke tempat-tempat suci, ke makam-makam orang besar atau pemimpin yang diagungkan, ke bukit atau ke gunung yang dianggap keramat, tempat pemakaman tokoh atau pemimpin sebagai manusia ajaib penuh legenda. Wisata religi yang dimaksud lebih mengarah pada wisata ziarah (wisata keagamaan) untuk mengunjungi makam/kubur.

Peziarah biasanya datang berombongan satu kampung, jamaah pengajian, atau komunitas lainnya. Namun, juga ada yang datang sendiri atau bersama keluarganya. Kedatangan mereka bisa karena nadzar atau kepentingan khusus, bisa pula didorong oleh motif mengunjungi tempat bersejarah atau tradisi mengunjungi makam tokoh yang dianggap berperan penting dalam sejarah hidupnya dan sejarah masyarakatnya. Terkait dengan paparan wisata religi di atas, ditunjukkan penelitian mengenai Form of Religious Tourism, menjelaskan bahwa wisata religi memiliki daya tarik tersendiri. Dengan nilai-nilai kerohanian dan toleransi antar umat beragama yang dapat menjadi pedoman bagi kehidupan. Sejalan dengan hasil penelitian tersebut, penelitian mengenai Epistemological aspects of Religious Tourism in rural areas, menjelaskan bahwa wisata religi merupakan fenomena yang berkembang memiliki sikap hormat terhadap leluhur. Khususnyaterhadap keberadaan suatu makam yang pada mulanya lekat pada nuansa spritual. Selain itu, paparan tersebut juga sejalan dengan hasil penelitian mengenai Entrepreneurship and Indigenous Enterpreneurs in Religious Tourism in India, menjelaskan bahwa perkembangan wisata religi di India mampu membangun semangat kebangsaan, aspresiasi terhadap seni budaya dan toleransi antar umat beragama.

Pengembangan wisata religi berdasar prinsip organisasi dilakukan oleh penelitian dilakukan pada makam Syekh Abdurrahman Siddiq, hasilnya menunjukkan bahwa pengembangan wisata religi makam Syekh Abdurrahman Siddiq dengan prinsip planning, organizing, actualing maupun controlling berjalan dengan baik. Faktor pendukungnya berasal dari masyarakat, instansi Dinas Pariwisata, serta pengelola makam Syekh Abdurrahman Siddiq, berhasil mengembangkan sarana dan prasarana yang memadai, suasana alam yang sejuk, keamanan dan kenyamanan serta obyek yang mengagumkan.

Berdasarkan kutipan di atas dapat disimpulkan bahwa pengembangan wisata religi mampu membangun semangat kebangsaan, aspresiasi terhadap seni budaya dantoleransi antar umat beragama. Selain itu, suatu destinasi obyek wisata, juga menyediakan pelestarian alam yang sejuk, sarana prasarana yang memadai, serta lingkungan yang nyaman. Berdasarkan latar belakang di atas, permasalahan penelitian ini meliputi bagaimana proses terbentuknya, pengembangan obyek wisata, dan dampak pengembangan yang ditimbulkannya. Sedang tujuannya meliputi mendiskripsikan proses terbentuknya, pengembangan obyek wisata, serta dampak pengembangan yang ditimbulkannya.

\section{METODE PENELITIAN}

Penelitian berjenis kualitatif, metode interaktif dengan studi kasus, yaitu pengembangan potensi pariwisata religi studi kasus pada makam Syekh Abdurrahman Siddiq Di Desa Teluk Dalam, Kecamatan Kuala Indragiri, Kabupaten Indragiri Hilir, beserta proses terbentuknya, pengembangan obyek wisata, dan dampak pengembangan yang ditimbulkannya.

Teknik pengumpulan datanya menggunakan teknik wawancara, observasi, dan dokumentasi. Validitas datanya menggunakan trianggulasi sumber data dan teknik. Sedangkan analisis datanya menggunakan teknik analisis data model interaktif. Dimulai dari pengumpulan data di obyek wisata religi makam Syekh Abdurrahman Siddiq, mereduksi data, mensajikan data, sampai penarikan kesimpulan. Proses tersebut dilakukan selama 4 bulan, sejak bulan Januari sampai April 2020.

\section{HASIL DAN PEMBAHASAN}

Latar belakang terbentuknya obyek wisata religi yaitu Syekh Abdurrahman Siddiq berawal dari 
runtuhnya kerajaan Indragiri. Salah satu Mufthi kerajaan Indragiriyaitu Syekh Abdurrahman Siddiq. Beliau mengajarkan ilmu agama kepada masyarakat seputaran Desa Sapat dan sekitarnya. Setelah meninggal makam Syekh Abdurrahman Siddiq dikeramatkan oleh warga masyarakat dan dijadikan obyek wisata religi, letaknya di desa Teluk Dalam Kecamatan Kuala Indragiri Kabupaten Indragiri Hilir. Banyak masyarakat luar maupun lokal datang berkunjung untuk melakukan ziarah atau mengenang jasa Beliau. Dengan maraknya kunjungan wisatawan, obyek wisata religi makam Syekh Abdurrahman Siddiq dilakukan pengembangan. Pengembangan yang dimaksud meliputi penambahan obyek wisata berupa Museum Syekh Abdurrahman Siddiq di desa Teluk Dalam Kecamatan Kuala Indragiri Kabupaten Indragiri Hilir. Sedangkan pengembangan obyek wisata agar lebih nyaman berupa menyediakan sarana tempat ibadah yang nyaman dan tempat istirahat yang sejuk. Selain itu, penambahan sarana pokok berupa gapura pintu masuk, atap untuk melindungi makam, dan Pundhen tempat untuk melindungi makam Syekh Abdurrahman Siddiq. Penambahan sarana pelengkap berupa tata tertib peziarah dan Masjid. Penambahan sarana penunjang berupa lahan tempat parkir, kantin, dan toko pakaian.Beberapa sarana yang belum dikembangkan secara optimal adalah perbaikan sarana pokok meliputi perbaikan pintu masuk ke makam dan perbaikan Masjid. Selain perbaikan sarana pokok, ada juga perbaikan sarana pelengkap, meliputi kondisi tempat wudhu dan toilet. Sedang pengembangan informasi untuk memperkenalkan obyek wisata kepada pihak luar berupa brosur, akses google internet dan buku legenda perjalanan Syekh Abdurrahman Siddiq. Pemanfaatan informasi tersebut, dapat meningkatkan kunjungan wisatawan karena informasi dimaksud mampu menggambarkan kelebihan, keunikan dan keunggulan yang dimiliki pada obyek wisata religi tersebut.

Pengembangan obyek wisata religi makam Syekh Abdurrahman Siddiq memberikan dampak positif bagi perekonomian masyarakat setempat. Terlihat dari berbagai bidang usaha di sekitar obyek wisata ini seperti toko pakaian, warung makan dan lapak pedagang kaki lima penjual jajanan seperti batagor, siomay, bakso bakar dan es dawet. Selain itu, juga membuka jasa tempat hiburan anak-anak seperti Kereta Mini, Kereta Kelinci dan toko mainan. Dengan berbagai bidang peluang usaha tersebut, penghasilan yang mereka peroleh mencapai Rp. 200.000 sampai Rp.900.000 perharinya.

\section{KESIMPULAN}

Berdasarkan hasil penelitian dan pembahasan yang telah dilakukan dapat disimpulkan bahwa terbentuknya obyek wisata ini bermula dari runtuhnya kerajaan Indragiri. Syekh Abdurrahman Siddiq membangun masjid sebagai sarana menyebarkan agama Islam di wilayah Sapat. Setelah meninggal dimakamkan di sekitar masjid. Makam tersebut dikeramatkan oleh masyarakat dan dijadikan obyek wisata religi. Banyak mas yarakat berkunjung untuk ziarah. Untuk itu dilakukan pengembangan, meliputipenambahan obyek wisata seperti Museum Syekh Abdurrahman Siddiq. Selain itu, penambahan sarana pokok berupagapura pintu masuk dan atap untuk melindungi makam. Sarana pelengkap berupa tata tertib peziarah dan masjid. Sarana penunjang berupa tempat parkir, kantin, dan toko pakaian. Sedangkan perbaikan sarana pelengkap berupa tempat wudhu dan toilet. Pengembangan informasi wisata meliputi memperkenalkan obyek wisata kepada pihak luar dan untuk meningkatkan kunjungan wisatawan. Hal tersebut dapat dilakukan dengan menggunakan brosur, akes layanan google internet. Dari pengembangan tersebut berdampak positif pada perekonomian masyarakat setempat. Terlihat dari tumbuhnya berbagai bidang usaha, seperti toko pakaian, warung makan, pedagang kaki lima, serta hiburan.

\section{REFERENSI}

A. Azhar, SYEKH ABDURRAHMAN SIDDIQ Tuan Guru Teladan Bangsa, vol. 1, no. 2. 2020.

A. Azhar, V. A. S. Maryanto, M. Apriyanto, and A. Samosir, "Penanganan Kejahatan Preman Pada Wilayah Hukum Polisi Resort Indragiri Hilir," Res Nullius Law J., vol. 2, no. 2, pp. 158-164, 2020.

A. Azhar and K. Novyar Satriawan Fikri, "Study of law number 9 off regarding freedom of speech in publice,” Int. J. Sci. Technol. Res., vol. 9, no. 1, pp. 4002-4006, 2020.

A. A. Lew, "A framework of tourist attraction research," Ann. Tour. Res., vol. 14, no. 4, pp. 553-575, 1987, doi: 10.1016/0160-7383(87)90071-5.

A. Pawlikowska-Piechotka, K. Gołębieska, N. Lukasik, A. Ostrowska-Tryzno, and K. Sawicka, "Rural Sanctuaries as 'Smart Destinations'-Sustainability Concerns (Mazovia Region, Poland)," Eur. Countrys., vol. 8, no. 3, pp. 304-321, 2016, doi: 10.1515/euco-2016-0022.

D. H. Olsen, "A Scalar Comparison of Motivations and Expectations of Experience within the Religious Tourism Market," Int. J. Relig. Tour. Pilgr., vol. 1, no. 1, pp. 41-61, 2013, [Online]. Available: 
https://www.researchgate.net/publication/302923603_A_Scalar_Comparison_of_Motivations_and_Exp ectations_of_Experience_within_the_Religious_Tourism_Market.

H. H. Adinugraha, M. Sartika, and A. Kadarningsih, "Desa Wisata Halal: Konsep Dan Implementasinya Di Indonesia," J. Hum. Falah, vol. 5, no. 1, pp. 28-48, 2018.

I. Masitah, "Pengembangan Desa Wisata oleh Pemerintah Desa Babakan, Kecamatan Pangandaran, Kabupaten Pangandaran,” Din. J. Ilm. Ilmu Adm. Negara, vol. 53, no. 9, pp. 1689-1699, 2019.

K. A. Shinde, "Entrepreneurship and indigenous enterpreneurs in religious tourism in India," Int. J. Tour. Res., vol. 12, no. 5, pp. 523-535, 2010, doi: 10.1002/jtr.771.

KMS. Novyar Satriawan Fikri and A. Azhar, "ACADEMIC STUDY OF DISTRICT FORMATION SOUTH INDRAGIRI,” Progress. LAW Rev., vol. 2, no. 1, pp. 1-13, 2020.

Kosim, Sutjitro, and Budiyono, "PERKEMBANGAN AGAMA ISLAM DI DESA WONOKERTO KECAMATAN SUKAPURA KABUPATEN PROBOLINGGO," Pancaran, vol. 2, no. 4, pp. 65-74, 2013.

M. Pourtaheri, K. Rahmani, and H. Ahmadi, "Impacts of Religious and Pilgrimage Tourism in Rural Areas: The Case of Iran,” J. Geogr. Geol., vol. 4, no. 3, pp. 122-129, 2012, doi: 10.5539/jgg.v4n3p 122.

M. Apriyanto, K. N. S. Fikri, and A. Azhar, "Pendampingan Santri untuk Penurunan Tingkat Pelanggaran Lalu Lintas," Magistrorum Sch. J. Pengabdi. Masy., vol. 1, no. 2, pp. 238-247, 2021, doi: 10.24246/jms.v1i22020p238-247.

Nashuddin, "The management of muslim spiritual tourism in lombok, Indonesia: Opportunities and challenges," J. Indones. Islam, vol. 10, no. 2, pp. 213-236, 2016, doi: 10.15642/JIIS.2016.10.2.213-236.

P. Rawis, J. Posumah, and J. Pombengi, "Pengembangan Objek Wisata Religius Dalam Meningkatkan Pendapatan Masyarakat Dan Pendapatan Asli Daerah (Pad) (Suatu Studi Pada Objek Wisata Bukit Kasih Toar Lumimu'Ut Kanonang Kabupaten Minahasa).," J. Adm. Publik UNSRAT, vol. 2, no. 029, p. 1298, 2015. 